\title{
Resenha
}

\section{A IMAGINAÇÃO SOCIOLÓGICA A SERVIÇO DA CRÍTICA CULTURAL}

OLIVEIRA, Augusto César de. Utopias simuladas: estudos sobre cotidiano e cinema. São Paulo: Annablume, 2012.

A sociologia de seu nascedouro até a contemporaneidade se arriscou, e assim persiste, em reflexões diversas acerca da relação existente entre a produção artística de uma dada época e a sua sociedade. A listagem de autores é extensa e citando apenas alguns nos ocorre Max Weber em seu hermético “Os Fundamentos Racionais e Sociológicos da Música”, cuja primeira aparição se deu em 1921, Theodor W. Adorno em sua perspectiva naturalmente interdisciplinar tratando especialmente da música em "Filosofia da Nova Música", contendo uma produção publicada inicialmente entre o final dos anos 1930 e a primeira metade da década de 1940 e, finalizando esta amostra radicalmente aleatória de estudos clássicos, o filósofo Georg Lukács, profundamente influenciado pelos debates da sociologia alemã, em 1914 publica "A Teoria do Romance" onde o romance burguês é compreendido como produto direto de uma dada sociabilidade emergente e radicalmente moderna.

$\mathrm{Na}$ sociologia vinculada ao chamado "novo movimento teórico", produção elaborada a partir da década de 1970, as incursões prosseguem sob novas tonalidades metodológicas e/ou epistemológicas. Irei citar apenas dois nomes com o mero objetivo de prosseguir ilustrando esta brevíssima contextualização do campo: o primeiro, Pierre Bourdieu, representando a sociologia francesa e o segundo, Niklas Luhmann, partícipe do neosistemismo alemão. Bourdieu em “As regras da arte”, publicado no Brasil em 1996 pela editora Companhia das Letras, analisa a produção estético-literária confrontada com os

\footnotetext{
${ }^{1}$ Doutorando em Ciência Política e Professor assistente de Ciência Política na Universidade Federal Fluminense (UFF).

${ }^{2}$ Termo apresentado em ALEXANDER, Jeffrey. O Novo Movimento Teórico. Revista Brasileira de Ciências Sociais. v.2, n.4, 1987.
} 


\section{A imaginação sociológica a serviço da crítica social}

recursos materiais e simbólicos desigualmente distribuídos na sociedade. Já na sociologia do alemão NiklasLuhmann, em seu "Die Kunst der Gesellschaft" (A arte da sociedade) de 1995, a arte é interpretada como um subsistema social constrangido ante os dilemas causados pela sua reivindicação de autonomia produtiva e a persistência da heteronomia enquanto condição inelutável.

No Brasil, o leitor desta subárea específica das ciências sociais encontra trabalhos concentrados especialmente na sociologia da literatura de Antonio Cândido ou em Roberto Schwarz, para citar dois expoentes da área, onde a produção romanesca é confrontada com a formação simbólica do Estado-Nação e de sua sociedade correlata. Usualmente, prospectando a construção do campo, parte das reflexões elaboradas por sociólogos brasileiros se apresenta em artigos esparsos disponíveis em periódicos ou reunidas em capítulos de livro ${ }^{3}$ sendo raras as obras elaboradas por autores individuais tendo por foco exclusivo a reflexão a partir da sociologia acerca da produção artística ${ }^{4}$.

Neste contexto, ocorrendo uma sociologia estrangeira seja clássica ou contemporânea que não ignora a arte como objeto e no Brasil, onde os produtos artísticos ainda carecem de uma maior atenção por parte dos sociólogos, "Utopias simuladas: estudos sobre cotidiano e cinema" de Augusto de Oliveira ocupa uma função especialmente importante. Oliveira é professor de sociologia no Departamento de Ciências Sociais da UFF/Campos dos Goytacazes-RJ, doutor na área pelo IUPERJ/UCAM e nos brinda com um conjunto de textos onde a produção cinematográfica e a música são apropriadas de modo a permitir um profundo exercício reflexivo sobre a sociedade contemporânea.

O livro, estruturado em seis capítulos e um apêndice, agrupa artigos publicados em periódicos acadêmicos nacionais, crônicas para a imprensa e textos inéditos elaborados pelo autor no decorrer dos anos 2000. As curtas crônicas musicais foram publicadas entre os anos de 2006 e 2007 no jornal Volta Cultural da cidade de Volta Redonda-RJ e abordam personagens diversos da música popular brasileira: Rita Lee, Roberto Carlos, Zé Ramalho, Ronnie Von, Gilberto Gil, dentre outros. Também são apresentados grandes movimentos,

\footnotetext{
${ }^{3}$ Vide por exemplo a coletânea organizada por Maria Lucia Bueno "Sociologia das Artes Visuais no Brasil" (Editora Senac, 2012).

${ }^{4}$ Não esquecendo Ligia Dabul com seu "Um percurso da pintura: a produção de identidades de artista" (Eduff, 2001) ou Hermano Vianna em seus “O Mundo Funk Carioca” (Jorge Zahar, 1988) e "O Mistério do Samba" (Jorge Zahar, 1996). Porém, tanto Dabul quanto Vianna militam especialmente na abordagem proporcionada pela antropologia em sentido lato ou na etnologia em sentido mais estrito. Pela sociologia propriamente, é digno de nota Sergio Miceli que elaborou trabalhos sobre a industria cultural brasileira e especialmente seu livro "Nacional Estrangeiro: história social e cultural do modernismo artístico em São Paulo", lançado em 2003 pela editora Companhia das Letras, cujo foco é centrado nas artes plásticas.
} 


\section{NORUS - v4, n.6, jul - dez 2016}

mesmo que de forma breve, como a Bossa Nova, a Tropicália e o universo dos "malditos" da indústria musical brasileira, este último formado por um fragmentado círculo de compositores que sequer articula uma "coletividade" propriamente dita. Ao colunista caberia (re)interpretar aspectos marcantes da trajetória dos artistas individuais e movimentos supracitados e, por vezes, mergulhar em obras paradigmáticas. O conjunto de crônicas, somando 14 textos, se apresenta na parte final do livro como apêndice.

Já quase a totalidade dos capítulos, onde alguns deles vieram a público no formato de artigo em periódicos como a tradicional Revista Achegas de Ciência Política e Alceu, revista do Departamento de Comunicação Social da PUC-Rio, trata especificamente de produções cinematográficas. Aqui há abordagens mais detidas, contrastando com as curtas crônicas musicais, sendo Scarface de Brian de Palma, A Casa da Mãe Joana de Hugo Carvana, Tropa de Elite de José Padilha e Edukators de Hans Weingartner objetos de capítulos solo. Ainda há dois capítulos restantes. Em um deles Oliveira elabora uma síntese analítica sobre a lógica da produção da indústria cultural debatendo em tonalidade crítica os lançamentos incessantes do cinema norte-americano, o que redundaria em um efeito alienante e nada reflexivo sobre o público. Como capítulo final, que precede o apêndice musical, o autor apresenta, utilizando o ensaio teórico como formato, um balanço não conclusivo sobre as utopias em nosso século.

A incomensurável constelação elaborada pela indústria cultural contemporânea é enfeixada pelo autor guiado por uma ambição que transcende a interpretação estritamente estética das obras e seus personagens reais ou fictícios. O objetivo de Oliveira é servir-se destes como trampolim para pensar dilemas constituintes do atual estágio civilizatório. As trágicas ironias das promessas não cumpridas pelo modo de produção capitalista, onde um suposto paraíso material concedido pelo consumo de massas e tendo a linguagem científica enquanto nosso princípio organizativo e quase teológico, redundaram em certo amargor e desencantamento. A sociedade real analisada é a que oferta soluções farmacológicas para as angustias subjetivas onde os indivíduos se espelham em bens culturais que, dialeticamente, tanto reforçam fantasias quanto prometem o inatingível dadas as situações concretas de existência. Por esta razão "a arte pela arte", lema por vezes simplesmente ingênuo, não ocupa lugar em qualquer linha do livro.

Em meio à predileção pelas obras artísticas selecionadas, há dois grandes temas incidentais a perpassar toda a obra: o mal-estar e o cotidiano. Oliveira se utiliza de filmes, discos e músicas para tratar da relativa onipresença do mal-estar civilizacional e observar o empobrecimento subjetivo no cotidiano brutalizado de nossos dias. O contexto sócio-histórico 


\section{A imaginação sociológica a serviço da crítica social}

com que o sociólogo se defronta, portanto, não é dos mais alvissareiros. Nosso zeitgeist é demarcado pelo esmaecimento das grandes utopias coletivas do século XX, notadamente a falência do horizonte humanista esmagado pela experiência trágica do socialismo real, o desbunde niilista da juventude após os libertários ventos soprados por 1968 e o quase completo desaparecimento do flower power $^{5}$ da década de 1970. O que se seguiu, da década de 1980 em diante, foi a prevalência de uma sociabilidade administrada por critérios de eficiência, a volatização do capital mediante a penetrante capilaridade da financeirização e uma conformação da subjetividade sequestrada pela sociedade de consumo.

Oliveira compreende, neste contexto, que há um processo de "simulação" de utopias. Sendo as mesmas esvaziadas em uma batalha fática perdida ante os imperativos sistêmicos do capitalismo, resta ao próprio mercado encontrar uma solução por simulacro. Ofertam-se "utopias simuladas", termo que dá título ao livro, em virtude da capacidade inerente dos seres humanos em vislumbrarem outro(s) futuro(s) possível(eis). Porém, são "simuladas" enquanto oferta artificial da indústria cultural em oposição às utopias autênticas, aquelas oriundas de movimentos coletivos de classe, gênero, geracionais ou étnicos. Ainda, sendo "simuladas" e intrinsecamente postiças, não conseguem saciar a sede dos agentes se não forem ofertadas em produção seriada. Isto inclusive talvez nos explique a produção dos blockbusters onde há as sequências intermináveis de vários filmes com inegável sucesso comercial. Por outro lado, não sendo elaboradas organicamente pelos agentes sociais, onde muitas vezes estes veem nas telas uma vida que jamais seria sua, a sensação de frustração e inadequação torna-se inevitável. Por essa razão, em uma sociedade profundamente pautada pelo consumo de imagens, o cinema é a arte que ocupa os capítulos mais densos do livro.

Este empreendimento feito pelo autor, onde mal-estar e cotidiano são pensados privilegiando a interpretação fornecida pela arte, não é feito de maneira canônica. Seja na forma ou no conteúdo, Oliveira exercita conscientemente uma abordagem transgressora. Primeiramente, ao lidar com questões inegavelmente complexas, as rígidas fronteiras disciplinares são solenemente ignoradas e/ou implodidas. A opção do autor é partir da

\footnotetext{
${ }^{5} \mathrm{O}$ movimento flower power surgiu nos últimos anos da década de 1960 nos países do Atlântico Norte e agregava parte da juventude em uma síntese de princípios normativos libertários, ocidentalização de religiões como o budismo e o hinduísmo, experimentalismo com o corpo e a mente, reconsideração dos valores tradicionais das relações afetivas, crítica da sociedade de consumo, etc... Igualmente defendia a não violência como premissa de interação na humanidade no mesmo contexto histórico em que transcorria tanto a guerra do Vietnã quanto os levantes da juventude duramente reprimidos no leste da Europa. Maiores detalhes sobre o pano de fundo cultural deste movimento podem ser consultados em "Ponto final: crônicas sobre os anos 1960 e suas desilusões" do jornalista norte-americano Mikal Gilmore, lançado no Brasil pela editora Companhia das Letras em 2010.
} 


\section{NORUS - v4, n.6, jul - dez 2016}

sociologia, onde concentra sua formação e apresenta alguns conceitos importantes para esta ciência humana (alienação, ideologia, etc...) amparado pela tradição marxista. Contudo, há um diálogo orgânico com a psicanálise que torna as interpretações sobre a subjetividade humana possível e a seleção de autores que inspiram Oliveira por esta trilha vai desde o pioneiro Herbert Marcuse até a renovada tradição crítica do esloveno Slavoj Žižek, onde a ênfase teórica gravita mais no continente lacaniano do que propriamente em Freud. Assim, especialmente o cinema é interpretado enquanto objetivação estética dos "sintomas" inerentes da contemporaneidade.

Nestes termos teóricos e interpretativos, onde as utopias são sequestradas e simuladas, além de apresentarem-se em sua versão pastiche, a análise do cinema oferece um panorama sombrio. Irei apresentar dois capítulos onde a relação mal-estar, cotidiano e cinema se apresenta de forma mais densa. Sobre Tropa de Elite nosso autor observa, ao flanar no camelódromo da Uruguaiana no Rio de Janeiro, a recepção possível do filme a partir das interpretações fornecidas pela classe trabalhadora que frequenta este importante centro comercial do Rio de Janeiro. Sendo estes sujeitos o objeto preferencial da violência policial nas periferias, enxergam no Capitão Nascimento afinidades com outros "heróis" do cinema norte-americano. A violência gratuita, mesmo que seja contra seus "iguais", é espetacularizada e recepcionada como exercício de mero entretenimento. Portanto, qualquer possibilidade reflexiva que esteja no filme é diluída e domesticada por um olhar viciado inerente à própria cultura de massas. Todavia, não contente com esta leitura, Oliveira busca em outros personagens reais, intelectuais da grande área de humanidades e em uma dona de casa, a diversidade interpretativa possível em sociedades culturalmente múltiplas. Para os intelectuais profissionais, sendo que estes não são citados por Oliveira no decorrer do capítulo, a obra de José Padilha é simplesmente fascista e uma apologia à violência do Estado, algo que produziu debates diversos na imprensa desde 2007, ano em que o filme foi lançado. Para a senhora dona de casa, o filme é um romance.

No capítulo sobre Scarface as complementaridades entre a permanência dos métodos moralmente questionáveis que propiciam a acumulação de capital e o vazio da sociedade de consumo assaltam o leitor na interpretação de Oliveira. Tony Montana, o personagem principal da obra de Brian de Palma, é analisado como uma espécie de tipo ideal das armadilhas do capitalismo avançado: é hipocritamente rejeitado pelo empresariado "moralmente legítimo", embora a violência (real ou simbólica) seja constituinte da acumulação de capital. Igualmente olha no fundo do abismo existencial guiado pelo consumo 


\section{A imaginação sociológica a serviço da crítica social}

cotidiano de drogas, sem desconsiderar que obtém uma vida de profunda abundância material. Neste tom, onde se apresentam as contradições entre aspirações subjetivas e as dissonâncias concretas do mundo social, o grande background do capítulo é sobre como o desejo é sequestrado por formas de viver onde mais uma vez são ofertados simulacros a partir das demandas legítimas de reconhecimento, realização e afetividade dos sujeitos na atual fase da sociedade.

Finalizando, o livro de Augusto de Oliveira nos apresenta o rico e crítico prefácio de Marcelo Lacombe ${ }^{6}$, precocemente falecido. Em um diálogo franco com a produção de Oliveira, Lacombe apresenta críticas e observações gerais que permitem tanto o leitor situarse no universo proposto pelo livro quanto apresenta uma síntese bastante original da diversidade de formatos e abordagens encontradas em Utopias Simuladas. Mas, para além disto, há uma narrativa que é preciosa para os leitores de ciências sociais. Lacombe contextualiza o estilo e as opções de Oliveira a partir da ótica geracional da formação dos cientistas sociais na não tão longínqua década de 1990. Justificando o estilo iconoclasta de Oliveira, Lacombe nos lembra que o período da formação de ambos, dado que compartilharam uma mesma contemporaneidade, é onde o ethos do homo lattes ${ }^{7}$ é forjado. Este ethos implica a adesão a um certo produtivismo e, de alguma maneira, um pensar adestrado ao qual conscientemente Oliveira se recusa a participar. Feita esta observação, e talvez até uma advertência, Utopias Simuladas torna-se relevante não só por seu conteúdo. A forma pela qual as abordagens e análises são realizadas abraçam, enquanto exercício de imaginação sociológica, justamente a autenticidade clamada por Oliveira em todo o livro. Por esta razão, dentre outras apresentadas no decorrer desta resenha, a obra lançada em 2012 que se encontra esgotada nas livrarias, mereceria uma segunda edição. Afinal, embora a sociologia guarde o potencial de alimentar a crítica da cultura, nem sempre esta ciência humana o faz de forma tão direta defrontando-se com a arte. Por isso, Oliveira e seu Utopias Simuladas engajam a sociologia e a imaginação sociológica a serviço da crítica cultural.

\footnotetext{
${ }^{6}$ Marcelo Santos Masset Lacombe finalizou sua carreira no momento em que era um promissor professor de sociologia na Universidade Federal do Recôncavo da Bahia. Durante sua trajetória acadêmica, interrompida por um acidente automobilístico no ano de 2011, apresentou produções no pensamento social brasileiro, sociologia do cotidiano e sociologia da arte. Ainda foi contemporâneo de Augusto de Oliveira durante a formação stricto sensu no antigo IUPERJ/UCAM no final dos anos 1990 e nos primeiros anos deste século. Como sentenciou Gabriel Cohn na ocasião do falecimento do cientista político alagoano Gildo Marçal Brandão (1949-2010), “A morte colheu Gildo Marçal Brandão em pleno voo". Penso que esta mesma avaliação cabe para Lacombe. A morte o colheu tragicamente em pleno vôo.

${ }^{7}$ Termo utilizado por Fréderic Vandenberghe em seu livro "Teoria social realista", publicado em 2010 em uma parceria entre a editora da UFMG e o IUPERJ/UCAM. Homo lattes é a maneira pela qual Vandenberghe nomina os cientistas sociais envoltos em "(...) múltiplos projetos de pesquisa e um estável plano de carreira" (VANDENBERGHE, 2010, p. 14).
} 